\title{
Implementasi Model Pembelajaran Kooperatif Tipe Course Review Horay (CRH) Terhadap Kemampuan Pemecahan Masalah Matematika
}

\author{
Nurhayati $^{1 *)}$, \& Novi Marliani ${ }^{2}$ \\ ${ }^{1.2}$ Universitas Indraprasta PGRI
}

\section{INFO ARTICLES}

\section{Article History:}

Received: 22-11-2019

Revised: 01-12-2019

Approved: 04-12-2019

Publish Online: 24-12-2019

\section{KeyWords:}

course review horay $(\mathrm{CRH})$ type of learning model, group to group exchange (GGE) type of learning model, mathematical problem solving ability

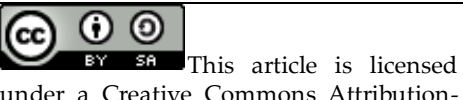

\begin{abstract}
The survey results showed $74 \%$ of students did not like mathematics. This has an impact on student achievement in mathematics. Therefore it is necessary to find a solution to the problem. Therefore to answer this problem the researchers conducted this study with the aim of finding the effect of the cooperative learning model type course review horay (CRH) on the ability to solve mathematical problems. SMAN 16 Bekasi is the place where this research was conducted, where researchers took class XI data. Samples of this study were 63 students who were divided into two classes where each class for the experimental class was 32 students and the classroom was 31 students. The sampling technique uses purposive sampling. Where consideration techniques taken are students who attend all meetings in learning activities. The research method used quasi-experimental with data analysis techniques with t test. The results of the study stated that there was a significant point score difference between the CRH and GGE groups, where the CRH class group scored higher than the chain answer group. It can be said that there is an effect of the cooperative review horay $(\mathrm{CRH})$ type of cooperative learning model on the ability to solve mathematical problems.
\end{abstract}

Abstrak: Hasil survei menujukkan $74 \%$ peserta didik tidak menyukai matematika. Hal ini berdampak pada prestasi peserta didik dalam matapelajaran matematika. Oleh karena itu, perlu dicarikan solusi atas masalah tersebut. Peneliti melakukan penelitian ini untuk menjawab masalah tersebut dengan tujuan untuk mencari pengaruh model pembelajaran kooperatif tipe course review horay $(\mathrm{CRH})$ terhadap kemampuan pemecahan masalah matematika. SMAN 16 Bekasi adalah tempat dilakukan penelitian ini, Peneliti mengambil data kelas XI. Jumlah sampel dari penelitian ini adalah 63orang peserta didik yang terbagi dalam dua kelas, tiap-tiap kelas untuk kelas eksperimen sebanyak 32 orang peserta didik dan kelas kontrol sebanyak 31 orang peserta didik. Teknik pengambilan sampel menggunakan purposive sampling. Teknik pertimbangan yang diambil adalah peserta didik yang mengikuti seluruh pertemuan yang dalam kegiatan pembelajaran. Metodepenelitian yang gunakan adalah eksperimen semu dengan teknik analisi data dengan uii t. Hasil penelitian menyatakan bahwa terdapat perbedaan skor point yang berarti antara kelompok course review horay (CRH) dan group to group exchang (GGE). Kelompok kelas CRH mendapat skor lebih tinggi daripada kelompok kelas GGE. Dapat dikatakan bahwa terdapat pengaruh model pembelajaran kooperatif tipe course review horay $(\mathrm{CRH})$ terhadap kemampuan pemecahan masalah matematika.

Correspondence Address: Jl. Raya Tengah, Pasar Rebo, Jakarta Timur; e-mail: nurhay_pdg@yahoo.co.id

How to Cite (APA $6^{\text {th }}$ Style): Nurhayati., \& Marliani, N. (2019). Implementasi Model Pembelajaran Kooperatif Tipe Course Review Horay (CRH) Terhadap Kemampuan Pemecahan Masalah Matematika. JKPM (Jurnal Kajian Pendidikan Matematika), Vol. 5(1): 29-36.

Copyright: Nurhayati., \& Marliani, N. (2019)

Competing Interests Disclosures: The authors declare that they have no significant competing financial, professional or personal interests that might have influenced the performance or presentation of the work described in this manuscript. 


\section{PENDAHULUAN}

Kegiatan pembelajaran di sekolah merupakan suatu langkah penting dalam mencerdaskan kehidupan bangsa. Salah satunya adalah pembelajaran matematika. Dengan belajar matematika, peserta didik dapat membangun pola pikir secara sistematis, logis dan konseptual. Pada kenyataannya, pembelajaran matematika di Indonesia masih terlalu rendah dibandingkan negaranegara berkembang lainnya.

Matematika masih dianggap sebagai pelajaran yang tidak menyenangkan karena sulit dipahami. Mungkin salah satu alasan mengapa banyak peserta didik beranggapan bahwa matematika itu sulit karena mereka belum atau tidak mengenal matematika. Alasan lain peserta didik beranggapan bahwa Matematika sulit karena merupakan ilmu pasti, yang selalu berhubungan dengan angka. Matematika selalu berhubungan dengan angka-angka yang rumit. Karena alasan itu, banyak orang yang malas atau tidak mau belajar matematika, terlebih jika bertemu dengan soal atau masalah matematika tak dapat menyelesaikannya. Pada akhirnya beranggapan matematika itu sulit.

Survei yang peneliti lakukan pada 50 anak secara acak pada peserta didik SMA 16 bekasi Membuktikan hal tersebut. Hasil survei menunjukkan bahwa $74 \%$ responden menyatakan bahwa mereka tidak menyukai matematika, hanya $18 \%$ yang menyukai matematika, dan sisanya $8 \%$ menyatakan bahwa mereka biasa saja dengan matematika. Matematika merupakan bidang studi yang dipelajari oleh semua peserta didik dari SD sampai SMA hingga perguruan tinggi, bertahuntahun telah diupayakan agar matematika dapat dikuasai peserta didik dan siswi dengan baik. Oleh ahli pendidikan dan ahli pendidikan matematika namun, hasilnya masih menunjukkan bahwa tidak banyak peserta didik yang menyukai matematika dalam setiap kelas (Turmudi, 2008:1).

Suwangsih dan Tiurlina (2006:188) menyatakan bahwa "Pemecahan masalah memegang peranan yang sangat penting dalam pembelajaran matematika". karena kemampuan memecahkan masalah matematika merupakan salah satu indikator dalam pembelajaran. Peserta didik dimungkinkan memperoleh pengalaman menggunakan pengetahuan serta ketrampilan yang sudah dimiliki untuk diterapkan pada pemecahan masalah yang bersifat tidak rutinbaik dalam proses pembelajaran maupun penyelesaiannya. Kemampuan pemecahan masalah sangat erat kaitannya dengan pola berpikir peserta didik. Oleh karena itu, dalam pemecahaan masalah diperlukan kemampuan dan pengalaman dalam memecahkannya. Kemampuan pemecahan masalah matematika sangat berguna dalam membantu peserta didik menyelesaikan soal-soal matematika yang berhubungan dengan kehidupan sehari-hari. Sering kali proses berpikir peserta didik dalam memecahkan masalah terlalu rumit. Mengingat pentingnya pelajaran matematika untuk pendidikan, guru diharapkan mampu merencanakan pembelajaran sedemikian rupa sehingga peserta didik akan tertarik dengan matematika.

Agar peserta didik dapat mencapai tujuan pembelajaran yang diharapkan diperlukanlah sebuah model pembelajaran yang inovatif yang mampu mengubah anggapan negatif tentang matematika, mengubah pola pikir peserta didik terhadap matematika dan menciptakan suasana belajar matematika lebih mudah dan menyenagkan agar peserta didik termotivasi untuk mempelajari matematika. Salah satu model pembelajaran yang dapat digunakan yaitu model pembelajaran kooperatif. Dalam pembelajaran kooperatif peserta didik diarahkan untuk belajar secara berkelompok dengan tujuan peserta didik lebih mudah menemukan dan memahami konsep matematika yang sulit. Selama belajar secara kooperatif, peserta didik tetap berada dalam kelompoknya. Mereka diajarkan untuk saling bekerja sama di dalam kelompoknya seperti menjadi pendengar aktif, memberikan penjelasan kepada teman kelompok dengan baik, berdiskusi, dan sebagainya.

Dalam model pembelajaran kooperatif, terdapat banyak variasi model yang dapat diaplikasikan diantarnya modelCourse Review Horay (CRH). Model Course Review Horay (CRH) memungkinkan guru untuk menciptakan suasana belajar yang baru bagi peserta didiknya di kelas. 
Sifat metode Course Review Horay (CRH) yang interaktif juga mampu membuat peserta didik lebih santai dalam mempelajari matematika.

Dwitantra (2010) mengatakan model pembelajaran Course Review Horay adalah "Suatu model pembelajaran dengan pengujian pemahaman menggunakan kotak yang diisi dengan nomor untuk menuliskan jawabannya, yang paling dulu mendapatkan tanda benar langsung berteriak hore".Dapat kita lihat dalam model pembelajaran ini peserta didik berlomba-lomba untuk mencari jawaban yang tepat. Selain itu, model ini diperlukan tingkat kemampuan pemahaman yang cukup agar peserta didik dapat lebih cepat menjawab soal.

Pada realitanya model pembelajaran Course Review Horay peserta didik tidak hanya belajar keterampilan dan isi akademik tetapi kerjasama yang menumbuhkan sikap yang positif di antara sesama peserta didik. Suprijono (2009:129) menyatakan bahwa, "Course Review Horay sebagai salah satu proses learning to know, learning to do, learning to be and learning to live together untuk mendorong terciptanya kebermaknaan belajar bagi peserta didik".

Selain model CRH masih banyak model-model pembelajaran yang dapat menimgkatkan keaktifan peserta didik dalam belajar matematika. Salah satu diantaranya adalah model group to group exchange (GGE) atau yang dikenal dengan pertukaran kelompok merupakan model pembelajaran aktif. Silbermen dalam Dharyani (2010:176) menyatakan "model GGE adalah memberikan tugas berbeda kepada para kelompok peserta yang kemudian setiap kelompok mengajarkan apa yang dipelajari kepada semua kelompok peserta". Metode GGE ini menuntut peserta didik untuk selalu aktif dalam pembelajaran, dan diminta untuk saling mengajarkan kepada sesama peserta didik.

Prayogo dan Ayu (2010:434) juga mengemukakan bahwa "model GGE adalah suatu format diskusi yang memberikan tugas-tugas yang berbeda diberikan kepada kelompok peserta didik yang berbeda". Model GGE menuntut peserta didik untuk berpikir tentang apa yang peserta didik pelajari, memberi kesempatan berdiskusi atau bersosialisasi dengan teman, bertanya dan berbagi pengetahuan kepada teman lainnya. Model GGE merupakan pembelajaran yang menerapkan langkah cepat, menyenangkan, mendukung, dan menarik hati.

Oleh karena itu, tujuan dari peneliti ini adalah untuk mengatahui pengaruh implementasi model pembelajaran kooperatif tipe course review horay $(\mathrm{CRH})$ terhadap kemampuan pemecahan masalah matematika. Dimana peneliti membandingkan kemampuan pemecahan masalah matematika pada kelas model pembelajaraan tipe CHR dengan kemampuan pemecahan masalah matematika pada kelas model pembelajaran GGE pada peserta didik kelas XI SMAN 16 Bekasi.

\section{METODE}

SMAN 16 Bekasi adalah tempat dilakukan penelitian ini. Peneliti mengambil data kelas XI. Jumlah sampel dari penelitian ini adalah 63orang peserta didik yang terbagi dalam dua kelas. Tiaptiap kelas untuk kelas eksperimen sebanyak 32 orang peserta didik dan kelas kontrol sebanyak 31 orang peserta didik. Teknik pengambilan sampel menggunakan purposive sampling, pertimbangan yang diambil adalah peserta didik yang mengikuti seluruh pertemuan yang dalam kegiatan pembelajaran.. Insturumen yang digunakan berupa studi literatur untuk model pembelajaran dan soal essai untuk kemampuan pemecahan masalah. Metodepenelitian yang kami gunakan adalah eksperimen semu dengan teknik analisis data dengan uji t. 
Tabel 1. Desain penelitian

\begin{tabular}{ccc}
\hline Kelas & Perlakuan & Tes \\
\hline Eksperimen & Course Review Horay $\left(\mathrm{X}_{1}\right)$ & $\begin{array}{c}\text { Pemecahan masalah } \\
\text { matematika }\left(\mathrm{Y}_{1}\right)\end{array}$ \\
\hline Kontrol & Group To Group Exchange $\left(\mathrm{X}_{2}\right)$ & $\begin{array}{c}\text { Pemecahan masalah } \\
\text { matematika }\left(\mathrm{Y}_{2}\right)\end{array}$ \\
\hline
\end{tabular}

\section{HASIL PENELITIAN}

Tahapan analisis data yang peneliti lakukan meliputi

a. Analisis deskriptif diantaranya mean, median, modus, standar deviasi

Tabel 2. Ringkasan statistik deskriptif

\begin{tabular}{|c|c|c|c|c|c|}
\hline \multicolumn{3}{|c|}{ Statistics } & \multicolumn{3}{|c|}{ Statistics } \\
\hline \multicolumn{3}{|c|}{ Kelas_CRH } & \multicolumn{3}{|c|}{ Kelas_GGE } \\
\hline \multirow[t]{2}{*}{$\mathrm{N}$} & Valid & 32 & $\mathrm{~N}$ & Valid & 31 \\
\hline & Missing & 0 & & Missing & 1 \\
\hline \multicolumn{2}{|c|}{ Mean } & 76.2812 & $\mathrm{Me}$ & & 66.7419 \\
\hline \multicolumn{2}{|c|}{ Median } & 79.0000 & $M e$ & & 66.0000 \\
\hline \multicolumn{2}{|c|}{ Mode } & 84.00 & $M o$ & & 78.00 \\
\hline \multicolumn{2}{|c|}{ Std. Deviation } & $1.00586 \mathrm{E} 1$ & Std & Deviation & $1.08565 \mathrm{E} 1$ \\
\hline \multicolumn{2}{|c|}{ Variance } & 101.176 & Var & ince & 117.865 \\
\hline \multicolumn{2}{|c|}{ Minimum } & 54.00 & & mum & 46.00 \\
\hline \multicolumn{2}{|c|}{ Maximum } & 90.00 & $M a$ & mum & 87.00 \\
\hline
\end{tabular}

b. Uji persyaratan data

Tabel 3. Hasil Uji Normalitas

One-Sample Kolmogorov-Smirnov Test

\begin{tabular}{llrr}
\hline & & Kelas_CRW & \multicolumn{1}{c}{ Kelas_GGE } \\
\hline $\mathrm{N}$ & & 32 & 31 \\
\hline Normal Parameters $^{a}$ & Mean & 76.2812 & 66.7419 \\
\cline { 2 - 4 } & Std. Deviation & 10.05865 & 10.85654 \\
Most Extreme & Absolute & .144 & .135 \\
\cline { 2 - 4 } Differences & Positive & .086 & .097 \\
& Negative & -.144 & -.135 \\
Kolmogorov-Smirnov Z & .816 & .753 \\
\hline Asymp. Sig. (2-tailed) & & .519 & .622 \\
\hline a. Test distribution is Normal. & & \\
\hline
\end{tabular}


Kriteria pengujian normalitas menyatakan bahwa jika nilai sig. > 0.05, maka data normal. Hasil pengujian normalitas diatas dapat dilihat Asymp sig. menyatakan 0.519 dan 0,622 ( > 0.05) hal tersebut menunjukkan bahwa kelompok kelas CRH dan kelompok kelas kontrol berasal dari data yang normal.

Tabel 4. Hasil Uji Homogenitas

Test of Homogeneity of Variances

\begin{tabular}{rrrrr}
\hline \multicolumn{4}{l}{ Kemampuan_Pemecahan_Masalah } \\
\hline $\begin{array}{l}\text { Levene } \\
\text { Statistic }\end{array}$ & df1 & df2 & Sig. \\
\hline .101 & & 1 & 61 & .752 \\
\hline
\end{tabular}

Signifikansi homogenitas $0.752(>0.05)$ menunjukkan variabel kemampuan pemecahan masalah pada kelompok perlakuan dan kontrol adalah homogen, dengan Levene Statistic0,101.

c. Hasil uji hipotesis

Tabel 5. Hasil Uji Hipotesis

Independent Samples Test

\begin{tabular}{|c|c|c|c|c|c|c|}
\hline & $\begin{array}{r}\text { Levene's } \\
\text { for Equa } \\
\text { Varian }\end{array}$ & $\begin{array}{l}\text { Test } \\
\text { lity of } \\
\text { ces }\end{array}$ & & t-test & for Equality of Mean & \\
\hline & $F$ & Sig. & $T$ & $D f$ & $\begin{array}{lc}\text { Sig. }(2- & \text { Mean } \\
\text { tailed) } & \text { Difference }\end{array}$ & $\begin{array}{l}\text { Std. Error } \\
\text { Difference }\end{array}$ \\
\hline $\begin{array}{l}\text { Kemampua Equal variances } \\
\mathrm{n} \_ \text {pemecaha assumed }\end{array}$ & .101 & .752 & 3.619 & 61 & 9.53931 & 2.63567 \\
\hline $\begin{array}{ll}\text { n_masalah } & \begin{array}{l}\text { Equal variances } \\
\text { not assumed }\end{array}\end{array}$ & & & 3.615 & 60.292 & 9.53931 & 2.63891 \\
\hline
\end{tabular}

Pada tabel Independent Samples Testbagiant-test for Equality of Meansterlihat nilai signifikansi 2 arah ( $t$-tailed $) 0.001<0.05$.maka disimpulkan terdapat perbedaaan yang signifikan antara rata-rata kemampuan pemecahan masalah antara kelas CRH dan Kelas GGE. Selanjutnya berdasarkan nilai t, diperoleh $t_{\text {hitung }}=3,619$ dan $t_{\text {tabel }}=2,000$, dimana $t_{\text {hitung }}>t_{\text {tabel }}$, mempunyai simpulan yang sama yaitu terdapat perbedaan rata-rata kemampuan pemecahan masalah antara kelas CRH dan Kelas GGE

\section{PEMBAHASAN}

Dari hasil perhitungan uji t dapat disimpulkan bahwa rata-rata kemampuan pemecahan masalahpeserta didik yang diajarkan dengan Pembelajaran Kooperatif tipe Course Review Horay $(\mathrm{CRH})$ lebih tinggi dari rata-rata hasil belajar matematika peserta didik yang diajarkan dengan Group To Group Exchange. Dengan kata lain, Pembelajaran Kooperatif tipe Course Review Horay $(\mathrm{CRH})$ dapat memengaruhi kemampuan pemecahan masalah matematika peserta didik. 
Hal ini dikarenakan dengan menerapkan Pembelajaran Kooperatif tipe Course Review Horay $(\mathrm{CRH})$, pemahaman peserta didik akan terasah kembali karena pelajaran akan diulang dalam setiap penerapannya. Dengan demikian, apabila metode ini diterapkan dengan baik, peserta didik dapat membuktikan dan menarik kesimpulan sendiri sehingga peserta didik dapat memiliki daya ingat dan pemahaman yang lebih baik lagi yang dapat meningkatkan pemecahan masalah tersebut. Hal tersebut sesuai apa yang diungkapkan Huda (2015: 229) bahwaMetode Course Review Horay merupakan metode pembelajaran yang dapat menciptakan suasana kelas menjadi meriah, menyenangkan, dan juga membantu peserta didik untuk memahami konsep dengan baik melalui diskusi kelompok.

Model Course Review Horay (CRH) juga mampu membuat suasana belajar menjadi lebih santai dan menyenangkan sehingga peserta didik dapat menerima materi dengan baik. Selain itu, peserta didik lebih termotivasi untuk lebih fokus dalam memperhatikan setiap materi yang diajarkan guru dan lebih aktif dalam mengikuti kegiatan pembelajaran yang telah direncanakan oleh guru mata pelajaran matematika. Selain dari pada itu guru dituntut untuk mengubah suasana pembelajaran di dalam kelas dengan lebih menyenangkan, sehingga peserta didik merasa lebih tertarik. Suasana tersebut menyebabkan peserta didik tidak bosan dalam belajarnya sehingga tercipta interaksi yang aktif dan menyenangkan. Hal inilah yang membuat tujuan pembelajaran matematika tercapai dengan maksimal.

Model pembelajaran CRH dapat memacu peserta didik untuk berkompetisi serta melatih kerjasama antarpeserta didik dalam menjawab pertanyaan-pertanyaan yang diberikan (Ani, Garminah, \& Suartama, 2016). Pernyataan tersebut sesuai dengan Tiga konsep sentral yang menjadi karakteristik pembelajaran sebagaimana dikemukakan Slavin (Isjoni, 2009: 33), yaitu 1) Penghargaan kelompok, penghargaan kelompok ini diperoleh jika kelompok mencapai skor diatas kriteria yang ditentukan. 2) Pertanggung jawaban individu, pertanggungjawaban ini menitikberatkan pada aktivitas anggota kelompok yang saling membentu dalam belajar. 3) Kesempatan yang sama untuk berhasil, setiap peserta didik baik yang berprestasi rendah atau tinggi sama-sama memeroleh kesempatan untuk berhasil dan melakukan yang terbaik bagi kelompoknya. Course Review Horay (CRH) mempunyai ciri-ciri selain pengembangan aktivitas berpikir juga menumbuhkan perilaku-perilaku sosial yang positif yang dapat dikembangkan melalui diskusi maupun kerja kelompok sehingga akan meningkatkan aktivitas peserta didik (Setiyaningsih, 2014).

Sedangkan dilain pihak, model pembelajaran GGE dianggap sesuai dengan standar kompetensi yang mengharuskan peserta didik belajar secara berkelompok, presentasi, tanya jawab, berbagi pengetahuan dengan yang lainya, dan menguasai materi baik yang diberikan oleh guru maupun teman sejawat. Dalam modelbelajar Group to Group Exchange peserta didik dituntut untuk menguasai materi karena setelah kegiatan diskusi kelompok berakhir, peserta didik akan bertindak sebagai guru bagi peserta didik lain dengan mempresentasikan hasil diskusinya kepada kelompok lain di depan kelas. Pada saat ini lah peserta didik membutuhkan keberanian dan kesiapan peserta didik untuk menjadi juru bicara.

Selain itu, dalam menjelaskan materi pelajaran seorang guru harus punya wawasan cukup luas, bahasa yang digunakan mampudimengerti oleh peserta didik. Hal inilah yang terjadi dilapangan, pada saat peserta didik menjelaskan materi, peserta didik kurang menguasai materi, bahasa yang digunakan tidak dimengerti sebagian peserta didik, dan terjadi ketidak kondusifan suasana kelas. Ini ternyata sesuai apa yang diungkapkan oleh Hosnan (2014) bahwa salah satu kelemahan dari model pembelajaran Group to Group Exchange (GGE) keterbatasan materi, peralatan, dan sumber daya. 


\section{SIMPULAN}

Simpulan penelitian ini menyatakan bahwa rata-rata kemampuan pemecahan masalah peserta didik yang diajarkan dengan pembelajaran kooperatif tipe Course Review Horay (CRH) lebih tinggi dari rata-rata hasil belajar matematika peserta didik yang diajarkan dengan Group To Group Exchange. Dengan kata lain, Pembelajaran Kooperatif tipe Course Review Horay (CRH) dapat mempengaruhi kemampuan pemecahan masalah matematika peserta didik

Model Course Review Horay (CRH) merupakan model suasana kelas lebih menyenangkan sehingga peserta didik tertarik dan berminat untuk mengikut pelajaran matematika. Peserta didik lebih termotivasi untuk fokus dan bekerja sama adalah hal yang terpenting dalam pembelajaran ini. Oleh karena itu dari hasi penelitian ini, seorang guru harus dapat menciptakan suasana kelas yang tidak monoton.

\section{UCAPAN TERIMA KASIH}

Pada kesempatan ini penulis sampaikan ucapan terimakasih kepada seluruh pihak yang telah memberikan bantuan kepada penulis. Terutama kepada kepala SMAN 16 Bekasi yang telah memberikan izin tempat penelitian. Ibu dan bapak guru yang telah rela diganggu oleh penulis karena kelasnya dijadikan tempat uji coba. Serta semua peserta didik yang sabar dan setia selama penelitian berlangsung. Tidak lupa pula kepada Ketua Program Studi Pendidikan Matematika, Universitas Indraprasta PGRI yang telah memberikan support kepada penulis untuk terus berkarya.

\section{DAFTAR RUJUKAN}

Ani, Ni Kadek, Garminah, Ni Nyoman, \& Suartama, I Kadek. (2016). Pengaruh Model Pembelajaran CRH Berbantuan Lks Peserta didik Kelas Iv SD. E-Journal PGSD Universitas Pendidikan Ganesha, 4(1).

Dharyani, Dani. (2010). 101 Cara Pelatihan dan Pembelajaran Aktif. Jakarta: Indeks

Dwitantra. 2010. Model Pembelajaran Course Review Horay (CRH). http://cheliemarlangen.blogspot.com/2013/02/model-pembelajaran-crhpadamatematika_4365.html. Diakses pada tanggal 22 April 2019.

Huda, Miftahul. (2015). Model-Model Pengajaran dan Pembelajaran. Yogyakarta: Pustaka Pelajar

Hosnan, 2014. Pendekatan Saintifik dan Kontekstual dalam Pembelajaran Abad 21. Bogor : Ghalia Indonesia

Isjoni. 2009. Cooperativ Learning. Bandung: Alfabeta.

Prayogo dan Ayu Silviana. (2010). Upaya Meningkatkan Prestasi Belajar Matematika Peserta didik dengan Pembelajaran Aktif Menggunakan Strategi Group to Group Exchange melalui Bantuan Tutor sebaya di Kelas X SMA Muhammadiyah 5 Karanggeneng Lamongan. Jurnal Semnas. Pendidikan Matematika dan Statistika UNIPA Surabaya

Setiyaningsih. (2014). Peningkatan Aktivitas dan Hasil Belajar Bentuk Pasar dengan Metode Course Review Horay (CRH) Berbantuan Media Gambar Kelas Viii Smp N 1 Bulu 
36 Nurhayati \& Marliani

Kabupaten Sukoharjo. Economic Education Analysis Journal, 2(3). Sugianti, U., \& Lesmono, A. D. S. (2017).

Agus Suprijono. 2009. Cooperative Learning, Teori \& Aplikasi PAIKEM. Surabaya: Pustaka Pelajar

Suwangsih dan Tiurlina. 2006. Model Pembelajaran Matematika.Bandung.UPI Press.

Turmudi, 2008. Landasan Filsafat Dan Teori Pembelajaran Matematika. Jakarta: Leuseur Cita Pusaka. 